University of Nebraska - Lincoln

DigitalCommons@University of Nebraska - Lincoln

Faculty Publications from Nebraska Center for Research on Children, Youth, Families, and Schools
Children, Youth, Families \& Schools, Nebraska

Center for Research on

2020

\title{
A Longitudinal Examination of Peer Victimization on Depressive Symptoms Among Asian American School-Aged Youth
}

Prerna G. Arora

Lorey A. Wheeler

Sycarah Fisher

Marymilt Restituyo

Jessica Barnes-Najor

Follow this and additional works at: https://digitalcommons.unl.edu/cyfsfacpub

Part of the Bilingual, Multilingual, and Multicultural Education Commons, Child Psychology Commons, Counseling Psychology Commons, Developmental Psychology Commons, Early Childhood Education Commons, Educational Psychology Commons, Family, Life Course, and Society Commons, and the Other Social and Behavioral Sciences Commons

This Article is brought to you for free and open access by the Children, Youth, Families \& Schools, Nebraska Center for Research on at DigitalCommons@University of Nebraska - Lincoln. It has been accepted for inclusion in Faculty Publications from Nebraska Center for Research on Children, Youth, Families, and Schools by an authorized administrator of DigitalCommons@University of Nebraska - Lincoln. 


\title{
A Longitudinal Examination of Peer Victimization on Depressive Symptoms Among Asian American School-Aged Youth
}

\author{
Prerna G. Arora, ${ }^{1}$ Lorey A. Wheeler, ${ }^{2}$ Sycarah Fisher, ${ }^{3}$ \\ Marymilt Restituyo, ${ }^{1}$ \& Jessica Barnes-Najor ${ }^{4}$ \\ 1 Department of Health and Behavioral Sciences, Columbia University, 525 W. \\ 120th Street, New York, NY 10027, USA \\ 2 Nebraska Center for Research on Children, Youth, Families and Schools, \\ University of Nebraska-Lincoln, Lincoln, NE, USA \\ 3 Department of Educational Psychology, University of Georgia, Athens, GA, USA \\ 4 Community Evaluation and Research Collaborative, Michigan State University, \\ East Lansing, MI, USA
}

Corresponding author — Prerna G. Arora, arora23@tc.columbia.edu

\begin{abstract}
The current study sought to examine the prospective relationship of peer victimization on changes in Asian American youth's depressive symptoms during early adolescence, a crucial period for the development of depression and engagement in peer victimization among youth. Further, as guided by cultural-ecological frameworks, the current study also sought to examine the role of school-based peer support and gender as moderators on the relationship between peer victimization and depressive symptoms among this understudied population. Participants included Asian American youth $(N=232$; $M$ age $=12.96, \mathrm{SD}=1.40 ; 51 \%$ girls) who completed questionnaires in the school context. Data for this study included two measurement occasions over a 1-year interval. Results indicated that high levels of adolescents' perceptions of peer victimization were associated with increased levels of depressive symptoms 1 year later. Additionally, results indicated that peer victimization interacted with reports of peer support within school, such that under conditions of moderate to high levels of school-based peer
\end{abstract}

Published in School Mental Health 12 (2020), pp 732-742.

DOI: $10.1007 /$ s12310-020-09383-w

Copyright (C) Springer Science+Business Media, LLC, part of Springer Nature 2020. Used by permission. 
support, high levels of peer victimization related to increased depressive symptoms. Findings contribute to our understanding of the development of depressive symptoms among early adolescent Asian American youth and have implications for school-based depression prevention programming for Asian American youth.

Keywords: Asian American, Early adolescents, Depressive symptoms, Peer victimization, School

\section{Introduction}

Asian Americans (AA), individuals with ancestral tries at least one country in the continent of Asia (Kiang, Tseng, \& Yip, 2016), are the fastest growing ethnic minority group in the USA (Hoeffel, Rastogi, Kim, \& Shahid, 2012). Specifically, by the year 2060, approximately one in 10 youth within the USA is expected to be of Asian origin (Asian American Federation, 2014). Research has pointed to significant racial and ethnic disparities in rates of depressive symptoms, with AA youth having higher levels of depressive symptoms than their White peers (Choi, Meininger, \& Roberts, 2006; Lorenzo et al., 2000). Further, as compared to their White peers, AA youth have been found to have increasingly chronic symptoms of depression (Brown et al., 2007). Moreover, AA girls have been found to have higher levels of depression when compared to AA boys and youth from other ethnic groups (Chen et al., 2011; Juang, Syed, \& Cookston, 2012). It is critical to understand factors that contribute to these disparities to be able to develop programming to promote positive development among this growing group in the USA.

\section{Peer Victimization Among AA Youth}

Cultural-ecological perspectives (e.g., García Coll et al., 1996) have purported that while the influence of various contextual factors (e.g., family, schools, neighborhoods) are salient to the development of all youth, these factors are likely experienced uniquely by racial and ethnic minority youth. In particular, sociocultural arguments have stated that such contextual factors are infused with culture and are thus experienced differently by individuals holding different cultural beliefs (Mistry \& Dutta, 2015). As such, the need to examine the distinct role of relevant risk and protective factors among racial and ethnic minority youth, including AA youth, has been made (Mistry et al., 2016). 
Numerous contextual variables have been identified as potential risk factors for the development of depression among AA youth (Wyatt, Ung, Park, Kwon, \& Chau, 2015). Among them, peer victimization, defined as physical, verbal, or psychological harassment of victims by perpetrators with the goal of causing harm (Gredler, 2003), has been noted of particular concern among AA youth. Fisher, Wallace, and Fenton (2000) found that while Black and Latino high school students reported more discrimination from adults, AA adolescents endorsed higher levels of victimization from peers. Further, Rivas-Drake et al. (2008) found that Chinese American adolescents reported higher levels of verbal harassment than their Black peers.

Early adolescence, which overlaps in time with the middle school years, has been underscored as a particularly vulnerable age for peer victimization among youth, including AA youth (Liang et al., 2007). This may be due to the greater importance placed on peer relationships during this time period (Pellegrini \& Long, 2004), the peak in rates of peer victimization (Carlyle \& Steinman, 2007), and psychological challenges associated with this age range and school setting (Harter, 1999). In one of the few examinations of peer victimization among AA early adolescents, Mouttapa et al. (2004) found that AA 6th graders were more likely than their Latino peers to be targets of peer victimization. With regard to gender, results have been mixed with some studies finding higher rates of peer victimization among AA boys (Cooc \& Gee, 2014) and others endorsing higher rates among AA girls (Koo, Peguero, \& Shekarkhar, 2012).

Peer victimization has been implicated in the development of depression among AA adolescents. In cross-sectional studies of Korean American (Shin, D’Antonio, Son, Kim, \& Park, 2011) and Chinese immigrant (Yeh et al., 2014) high school-aged youth, adolescents who reported experiencing peer victimization reported higher levels of depressive symptoms. However, despite early adolescence serving as a critical time in the development of depressive symptoms among youth (Rohde et al., 2009), including AA youth (Greenberger \& Chen, 1996), as well as in experiencing peer victimization (Carlyle \& Steinman, 2007; Liang et al., 2007), no research, to our knowledge, has examined the role of peer victimization on the development of depressive symptoms among AA youth during this developmental period. Moreover, no research has examined the relationship among these variables over time. 


\section{Peer Support as a Buffer for Depressive Symptoms Among AA Youth}

Socio-ecological models have underscored the importance of peer support, or emotional support from and closeness to a best friend, a peer group, or classmates, as a protective factor which can mitigate or buffer the negative outcomes associated with bullying (e.g., Espelage \& Swearer, 2010). Research has examined the potential buffering role of peer support on depression among victimized youth. For instance, in a one-year longitudinal study of 393 elementary school-aged FrenchCanadian youth, peer victimization related to increases in depressive symptoms only for youth without significant peer friendships (Hodges, Boivin, Vitaro, \& Bukowski, 1999). Additionally, in a large sample of middle and high school youth (52.9\% White, 34.3\% Black, 5.7\% Latinx, 1.3\% Asian), Holt and Espelage (2007) found that moderate social support from close friends protected against depressive symptoms among victims of bullying.

Considering differences in levels of social support (Rueger et al., 2008) and depression (Nolen-Hoeksema, 2001) by gender, studies have also sought to examine gender differences in the buffering role of peer support on depressive disorders. For instance, in a cross-sectional study of 355 middle school students ( $97 \%$ White), classmate support moderated the relationship between peer victimization and internalizing distress among boys, but not girls (Davidson \& Demaray, 2007). Similarly, in a cross-sectional study of 544 middle school-aged victims of peer victimization (40\% Latino, 30\% English Language Learners), support from a close friend buffered the manifestation of depressive symptoms for boys, but not girls (Tanigawa, Furlong, Felix, \& Sharkey, 2011). Conversely, a study of elementary school-aged youth (54\% Latinx, 34\% White), Schmidt and Bagwell (2007) found that peer support from a best friend served as a buffer against depressive symptoms from peer victimization for girls only. Thus, findings regarding the moderating role of gender on this relationship have been inconclusive.

AA populations hold unique cultural values and experiences related to acculturation processes that may influence peer relationships. Thus, the literature has underscored the need to examine within-group variation of the role of peer support among AA adolescents (Okagaki \& Bojczyk, 2002). For instance, because AA youth are believed to acculturate more quickly than their parents, they are believed to obtain less parental 
support, thus potentially being in greater need of peer support (Kim \& Goto, 2000). However, limited research has examined the role of peer support as a protective factor in the development of depression among AA youth. The scant literature suggests mixed findings. In a cross-sectional study of Chinese American adolescents, emotional peer support served as a buffer between discrimination and depressive symptoms (Grossman \& Liang, 2008). However, in a cross-sectional study of lowincome Chinese American older high school-aged youth, emotional support from peers was not found to act in a protective role in the relationship between various risk factors, including peer victimization, and depressive symptoms (Yeh et al., 2014). Considering conflicting findings and limited existing research, clarification of the role of peer support as a protective factor in the development of depressive symptoms, as well as the moderating role of gender in this relationship among AA early adolescents, is needed.

\section{Current Study}

Despite the high prevalence of peer victimization (Mouttapa et al., 2004) and the cross-sectional link between peer victimization and depression (Shin et al., 2011; Yeh et al., 2014) among AA adolescents, no research has examined the prospective role of peer victimization on the development of depressive symptoms among AA early adolescents. Early adolescence is a critical time in the development of depression and peer victimization, and an understanding of relationships during this developmental period could inform future work on preventive interventions. Moreover, limited research has examined the protective role of peer support on the development of depression among AA early adolescents; it is critical to understand variation within this group given the unique cultural and environmental contexts of this growing population in the USA (Okagaki \& Bojczyk, 2002). Further, though past research has found differences in the association between peer victimization and depression by gender (e.g., Schmidt \& Bagwell, 2007; Tanigawa et al., 2011), to our knowledge, no research has examined the role of gender as a moderator of this relationship among AA youth.

The aim of the current study was to examine the role of peer victimization on changes in AA youth's depressive symptoms during early adolescence, a crucial period for the development of depression and 
engagement in peer victimization among youth. To rule out plausible alternative explanations based on interpersonal theories of depression and transactional models that suggest that depression may be both an antecedent and consequence of peer victimization (Rudolph, 2009), the current study also examined the potential reciprocal associations between depressive symptoms and peer victimization over time. A secondary aim of the current study was to examine the role of peer support within the context of school and gender as moderators of the relationship between peer victimization and depressive symptoms among AA early adolescents. We hypothesized that higher levels of adolescents' perceptions of peer victimization would be associated with increased levels of youth depressive symptoms over time. Considering conflicting past research regarding the protective function of peer factors on the development of youth depressive symptoms, as well as role of moderating role of gender on the relationship between peer victimization and depressive symptoms, we sought to clarify these relationships among a sample of early adolescent AA youth.

\section{Method}

\section{Procedures}

Data for this study come from the Coordinated Community Student Survey (CCSS), a collaborative effort between researchers and educators that began in 2004. Data were collected over five years from primary and secondary students in a Midwest area comprised of 102 urban, suburban, and rural schools (Barnes et al., 2009). On average, the ethnic composition of study schools for AA students was 1.34 percent ( $S D=1.24$ ). Demographic data for the larger area indicate that approximately $0.9 \%$ of the population identifies as AA (U.S. Census Bureau, 2010). The purpose of the larger study was to gather data on student health and wellbeing and the contextual factors important in students' lives. The collaborative collected data from 4 th through 12 th grade students in the spring of each year. Consent forms were distributed to the parents of all students in participating schools via student backpacks and home mailings yearly. An average of $50 \%$ of students enrolled in the participating schools provided written parental consent to participate in the 
study (approximately 12,000 students per year). Research staff administered surveys at each participating school during school hours to all students whose parents provided written consent. Both paper surveys and Internet-based surveys, depending upon each school's testing capacity, were used; survey completion took approximately 30 to 45 min for students. For this study, data for individuals were de-identified and included the original items and scale scores relevant to this project. No compensation was offered for participation in the study. Institutional Review Board approval was obtained from the principal investigator's (PI) primary institution.

\section{Participants}

Based on the goals of the current study, we used the AA subsample of 232 5th-9th grade students ( $51 \%$ girls; $M$ age $=12.96, \mathrm{SD}=1.40$ ), $1 \%$ of the total sample. The current sample included Asian American youth who responded to the survey at least once over the five years of the study. Adolescents' first response to the survey was considered Time 1 (T1) data. Time 2 (T2) data were collected 1 year after T1. Youth attended 56 different schools (14\% elementary, 65\% middle, and $20 \%$ high schools) at Time 1 (included in analysis to adjust for clustering). Most of youth reported not moving in the prior year (59\%). Attrition analyses between youth who completed the T2 assessment $(n=78)$ and those who did not $(n=154)$ suggested no differences on study variables. On demographic variables, the only difference was that those who took the survey a second time were in a younger grade, $M=6.68, \mathrm{SD}=1.33$, than those who did not, $M=7.30, \mathrm{SD}=1.37 ; t(230)=3.28, p=.001$. We, thus, include grade as a covariate in all analyses. Grade did not relate to differences in depression at T2, $F(4,73)=.14, p=.967$, suggesting missingness due to grade did not relate to differences in our outcome variable.

\section{Measures}

Adolescents completed the CCSS, an instrument designed to assess self-reported student's attitudes, beliefs, and behaviors (Barnes et al., 2009). The CCSS is a 208-item questionnaire regarding student physical, social, and psychological functioning using reliable and valid, multi-item 
scales that were selected by the faculty and community members of the Coordinated Community Collaborative from public and peer-reviewed sources that had known psychometric properties (e.g., Michigan 21st Century Statewide Evaluation, California Health Kids Survey, the Centers for Disease Control and Prevention's YRBS survey, and the SEARCH Institute's 40 Developmental Assets for Adolescents instrument; Barnes et al., 2009). All measures that we describe below come from this instrument administered in the larger study.

Depressive Symptoms (T1, T2)

Adolescents reported on their experiences of depressive symptoms in an adapted 13-item measure based on the 20-item Center for Epidemiologic Studies Depression Scale (CES-D; Radloff, 1977). For the current study, the stem was changed from "During the past week" to "During the past year, how often did the following things happen?" to be in line with other measures as part of the yearly data collection process. In addition, the wording was changed on two items to be more appropriate for adolescents (i.e., "My sleep was restless" to "I had a hard time sleeping"; "I had a crying spell" to "I felt like crying"). The measure was also reduced from 20 items to 13 items for brevity. Adolescents reported on a 4 -point Likert scale from $1=$ not at all to $4=a l o t$. We included T1 depressive symptoms in analyses as a control variable meant to covary out the effect of prior levels of youth's symptoms. We summed the items to get a total score, with high scores representing high levels of depressive symptoms, consistent with prior work (Radloff, 1977). Internal consistency was good (T1 $\alpha=.90 ; \mathrm{T} 2 \alpha=.88)$.

\section{Peer Victimization $(\mathrm{T} 1, \mathrm{~T} 2)$}

Peer victimization was measured using adolescents' reports on a 13item measure that captures the frequency of their personal experiences with social exclusion, physical aggression, and name-calling within the school context. Adolescents reported "in the past year, how often did the following things happen" (e.g., "A kid at my school teased me about my body") on a 4 -point Likert scale $(1=n e v e r$ to $4=a$ lot $)$. Confirmatory factor analyses suggested the best structure was a one-factor solution (compared to two-factor solution: $\Delta \chi^{2}(1)=43.21, p<.001$ ). For the one-factor solution, model fit was adequate, $\chi^{2}(63)=171.48, p<.001$; 
RMSEA $=.086,90 \%$ CI $[.07, .10]$; SRMR $=.066$; and factor loadings were above $.50(p<.001)$. Two sets of items had correlated errors due to similar wording (i.e., "A kid at my school teased me about my body" and "A kid at my school teased me about the way I look"; "A kid at my school hit or pushed me when they were not playing around" and "A kid at my school said he or she was going to hurt me"). We averaged all items to create a total score, with high scores representing high levels of victimization. Internal consistency was good $(\alpha=.89)$.

\section{School-Based Peer Support (T1)}

Adolescents reported on four items related to school-based peer support. Adolescents report on their experiences with their peers in the school context (e.g., "There are students at my school who really care about me") on a 4-point Likert scale ( 1 = strongly disagree to $4=$ strongly agree). Three of the items were negatively worded and reverse-coded to indicate peer support (i.e., "It is hard to make friends at my school"; "I feel alone when I am at my school"; "I usually spend lunch and/or recess time alone at my school"). We averaged the items to get a total score, with high scores representing high levels of peer support at school. Internal consistency was good $(\alpha=.81)$. Items for this measure were developed by the PI based on a review of peer support items in frequently used school climate surveys and have been used in other published studies (e.g., Arora et al., 2017; Fisher, Wheeler, Arora, Chaudry, \& BarnesNajor, 2019).

\section{Demographic Information (T1)}

Adolescents reported on their gender ( $0=$ girls, $1=$ boys $)$, grade, and family mobility. The current study did not collect a direct measure of family socioeconomic status (SES); thus, family mobility was used as a proxy. Family mobility has been suggested as a proxy for SES as students in the USA with less housing stability due to financial restraints (i.e., loss of jobs, insecure or temporary housing) are more likely to move more frequently (Bradley \& Corwyn, 2002; McLoyd, 1990; National Center for Education Statistics, 2012). Family mobility was based on student reports on the following item: "How many times have you moved into another home or apartment in the past year?" with responses from $0=n o$ times to $4=4$ or more times. 


\section{Analytic Approach}

To address the study aims, we used path analysis with full information maximum likelihood estimation robust (FIMLR) option in Mplus 7.3 (Muthén \& Muthén, 1998-2014) to improve estimation and retain power under conditions of missing data (Enders, 2010). FIML-R has been found to produce robust, less biased estimates under conditions of large amounts of missing data (Enders, 2010). Additionally, the methodological literature currently recommends including variables that are either related to the analytic variables that have missing data (i.e., T2 depressive symptoms) or related to missingness (Enders, 2010). Thus, we included T1 depressive symptoms as it was correlated with T2 depressive symptoms, $r=.55$, and grade based on the attrition analyses (reported previously in Participants section). This was in part to make the missing at random (MAR) missing data assumption more plausible, reduce bias, and improve statistical power. We used adolescents' school using the Mplus CLUSTER command in the path models to adjust for interdependence in the study design related to schools (i.e., appropriately adjusts standard errors for nesting). The covariates of student gender $(0=$ girls, $1=$ boys), grade, family mobility, and $\mathrm{T} 1$ depressive symptoms were included in all models.

To address our first aim, we estimated a model that included T1 peer victimization as the independent variable (IV) and T2 depressive symptoms as the dependent variable (DV). To examine plausible alternative models, we estimated a second model that added $\mathrm{T} 2$ peer victimization as an additional DV to determine the possible reciprocal nature of associations between depressive symptoms and peer victimization. To address our second aim, we then added our T1 moderator variable (i.e., peer support) to the model from Aim 1 with T2 depressive symptoms as the DV. To test for moderation, we included in the path model terms created by the interaction of each potential moderator and peer victimization (e.g., peer support $X$ victimization), as well as the three-way term including gender. Prior to the creation of the interaction terms, we centered all variables to reduce multi-collinearity. The final model included only significant interactions, as retaining interactions that are not significant increases standard errors (Aiken \& West, 1991). We conducted follow up analyses for significant interactions as outlined by Aiken and West (1991), including testing for significant simple slopes + 1 SD above and -1 SD below the mean. 
Table 1. Descriptive statistics and correlation for study variables $(N=232)$

\begin{tabular}{lccccccc} 
Variables & 1 & 2 & 3 & 4 & 5 & 6 & 7 \\
\hline 1. Gender & - & & & & & & \\
2. T1 grade & - & $.12 \dagger$ & - & & & & \\
3. T1 family mobility & .03 & -.03 & - & & & & \\
4. T1 peer victimization & $.20^{*}$ & .08 & $.24^{*}$ & - & & & \\
5. T1 peer support & $-.15^{*}$ & -.05 & -.15 & $-.46^{*}$ & - & & \\
6. T1 depressive symptoms & .03 & .09 & $.15^{*}$ & $.53^{*}$ & $-.47^{*}$ & - & \\
7. T2 depressive symptoms & -.12 & $.16 \dagger$ & .00 & $.49^{*}$ & $-.30^{*}$ & $.55^{*}$ & - \\
$M$ & .49 & 7.09 & .60 & 1.77 & 3.33 & 26.94 & 26.09 \\
SD & .50 & 1.39 & .93 & .60 & .67 & 8.96 & 8.19 \\
\hline
\end{tabular}

T1 = Time 1 . T2 = Time 2 ( 1 year later $)$. Gender coded as $0=$ girls, $1=$ boys

$\dagger p<.10 ; * p<.05$

\section{Results}

We organized the results around the research aims and begin by presenting findings for the first aim, the examination of the prospective association between adolescents' peer victimization (T1) and depressive symptoms (T2) reported on 1 year later (controlling for prior levels of depressive symptoms at T1, as well as T1 youth gender, grade, and family mobility as covariates). Then, we present results for the second aim, examining the roles of peer support in the school context and gender, above and beyond the effects of peer victimization and the covariates as tested for Aim 1. Table $\underline{1}$ shows descriptive statistics (i.e., means and standard deviations) and bivariate correlations for all study variables.

The model estimated in addressing our first aim explained a large proportion of variance in AA adolescents' depressive symptoms $\left(R^{2}=.41\right.$; Table 2, Model 1). Consistent with our hypotheses, high levels of adolescents' perceptions of peer victimization (T1) were associated with increased levels of depressive symptoms (T2) reported on 1 year later, $\beta=$ $.35, p<.05$. Of the covariates, gender $(\beta=-.19, p<.05)$ and T1 depressive symptoms $(\beta=.38, p<.05)$ were related to T2 depressive symptoms. Girls had increased levels of depressive symptoms. The second model estimated to examine the reciprocal nature of associations between depressive symptoms and victimization, provided further support for the study's hypothesis and failed to provide support for alternative claims. In particular, once $\mathrm{T} 2$ victimization was added to the model, that association between $\mathrm{T} 1$ victimization and $\mathrm{T} 2$ depressive symptoms remained, 
Table 2. Results of path analyses predicting T2 Asian American adolescents depressive symptoms

\begin{tabular}{|c|c|c|c|c|c|c|}
\hline \multirow[t]{2}{*}{ Parameters } & \multicolumn{3}{|c|}{ Model 1} & \multicolumn{3}{|c|}{ Model 2} \\
\hline & $b$ & se & $\beta$ & $b$ & se & $\beta$ \\
\hline \multicolumn{7}{|l|}{ Covariates } \\
\hline Gender & $-3.03^{*}$ & 1.22 & -.19 & $-2.72^{*}$ & 1.30 & -.17 \\
\hline $\mathrm{T} 1$ grade & .39 & .46 & .84 & .38 & .40 & .07 \\
\hline T1 family mobility & -1.20 & 1.00 & -.14 & -.94 & .90 & -.11 \\
\hline T1 depressive symptoms & $.35^{*}$ & .11 & .38 & .31 & .10 & .34 \\
\hline \multicolumn{7}{|l|}{ Predictor } \\
\hline $\mathrm{T} 1$ peer victimization & $4.83^{*}$ & 1.74 & .35 & $5.99 *$ & 1.40 & .44 \\
\hline \multicolumn{7}{|l|}{ Moderator } \\
\hline $\mathrm{T} 1$ peer support & & & & -1.36 & 1.30 & -.11 \\
\hline \multicolumn{7}{|l|}{ Interaction terms } \\
\hline Peer victimization $\times$ support & & & & $4.41^{*}$ & 1.50 & .33 \\
\hline$R^{2}$ & $.41^{*}$ & .11 & & $.47^{*}$ & .07 & \\
\hline
\end{tabular}

$N=232 . \mathrm{T} 1=$ Time $1 . \mathrm{T} 2=$ Time 2 (1 year later). All variables were centered. The final model presented includes only significant $(p \leq .05)$ interaction terms (Aiken \& West, 1991)

$* p<.05$

$\beta=.34, p=.007$. The association between T1 depressive symptoms and T2 victimization was not significant, $\beta=-.05, p=.65$.

For our second aim, the model explained additional variance in AA adolescents' depressive symptoms $\left(R^{2}=.47\right.$; Table $\underline{2}$, Model 2). We found that peer victimization interacted with reports of school-based peer support, $b=4.41, p<.05$. Tests of simple slopes revealed that under conditions of high levels of peer support, high levels of peer victimization related to increased depressive symptoms, $b=8.94, S E=1.62, p<.001$ (Fig. 1). Conversely, under conditions of low levels of peer support, there was no significant associations, $b=3.04, S E=1.86, p=.10$. There was no gender moderation of the direct effects or in the three-way by schoolbased social support.

\section{Discussion}

Despite high rates of peer victimization among AA youth (Mouttapa et al., 2004), and the role of peer victimization as a risk factor for the development of depressive symptoms (Shin et al., 2011; Yeh et al., 2014), limited research examining this relationship among the AA population 


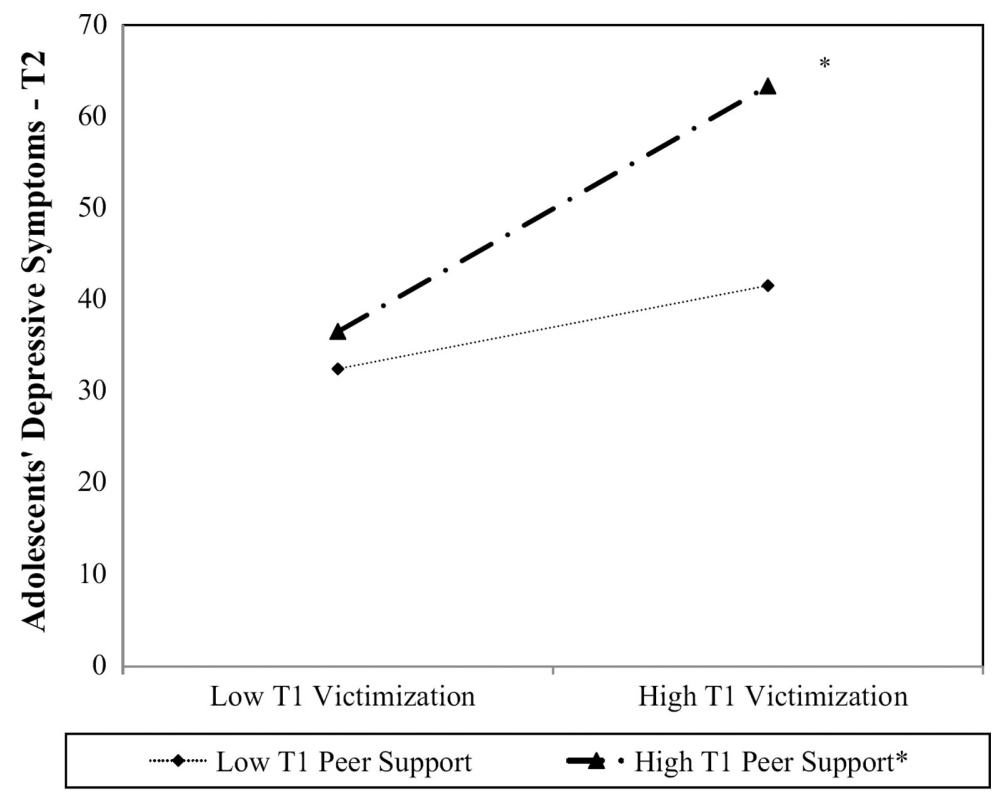

Fig. 1. Association between Asian American adolescent's peer victimization and depressive symptoms (reported on 1 year later) as moderated by peer support (in school).

has been conducted, with existing research having only examined this relationship in cross-sectional samples of older AA adolescents. Further, despite the unique cultural and environmental contexts of this growing population in the USA (Okagaki \& Bojczyk, 2002), the role of schoolbased peer support as a potential moderator in the relationship between peer victimization and depressive symptoms for AA boys and girls requires additional clarification. Thus, the current study aimed to examine the prospective relationship between peer victimization and depressive symptoms in a sample of AA early adolescents, and the moderating roles of school-based peer support and gender on this relationship. Understanding these relationships will assist in the development of culturally specific and ecological interventions to decrease the impact of peer victimization on AA youth.

\section{Peer Victimization and Depressive Symptoms}

In line with past theory which has argued that peer victimization plays a key role in the development of depression via attacks on peergroup rank (Gilbert, 1992) and threats to social bonds (Baumeister \& 
Leary, 1995) thus leading to social isolation, the first aim examined the prospective relationship between peer victimization and depressive symptoms for AA youth. Results indicated that AA youth who report higher levels of perceived victimization also report increased levels of depressive symptoms 1 year later. This finding is consistent with past cross-sectional research that has examined the relationship between peer victimization and depressive symptoms among AA youth (Shin et al., 2011; Yeh et al., 2014). Results from this study add to existing research by examining this relationship longitudinally and extending these findings to early adolescent AA youth, a critical period for the development of depression and engagement in peer victimization (Carlyle \& Steinman, 2007; Rohde et al., 2009).

This study failed to find support for alternative models of peer support and depressive symptoms. Specifically, recent research, building on interpersonal theories of depression which have underscored the negative impact depression on the development of social skills resulting in subsequent interpersonal difficulties (Rudolph, 2009), has sought to examine a transactional model of peer victimization and depression. Specifically, these studies have found support for the cyclical nature of depressive symptoms and peer victimization (Kaltiala-Heino, Fröjd, \& Marttunen, 2010; Kawabata, Tseng, \& Crick, 2013; Sweeting, Young, West, \& Der 2006). Other studies, however, have found support for a unidirectional effect, either that of peer victimization leading to depressive symptoms (Bond et al., 2001; Schwartz et al., 2005) or for the role of depressive symptoms in eliciting peer victimization (Kochel, Bagwell, Ladd, \& Rudolph, 2017; Kochel, Ladd, \& Rudolph, 2012; Sentse, Prinzie, \& Salmivalli, 2016; Tran, Cole, \& Weiss, 2012). The literature has examined early adolescent samples both within the USA and Europe, yet, to date, AA youth have primarily been excluded from these examinations. This study builds on the limited research on the transactional model of peer victimization and depressive symptoms among AA early adolescent youth.

\section{Moderating Role of Peer Support}

It is critical to identify ways to diminish the impact of peer victimization on youth. Peer support is one such factor that may lessen the deleterious impact of victimization on depressive symptoms for AA early 
adolescent youth (Grossman \& Liang, 2008). Thus, the moderating role of school-based peer support on the relationship between peer victimization and depressive symptoms in AA early adolescent youth was examined. Peer support within the school context interacted with peer victimization such that, in the context of higher levels of peer support, high levels of peer victimization in school were associated with increased levels of depressive symptoms a year later. We did not find support for moderation by gender.

Other researchers have found similar results. Specifically, a longitudinal study conducted by Desjardins and Leadbeater (2011) found that relationally victimized adolescents (85\% White) who reported high levels of emotional support from peers were more likely to experience increases in depressive symptoms compared to those who reported low levels of peer emotional support. There are a number of potential reasons for this counterintuitive finding. The first is that whereas youth may have meaningful relationships with peers, these peers may serve as a sounding board upon which to discuss experiences of peer victimization, leading to co-rumination (Rose, 2002). According to Rose (2002), co-rumination refers to "excessively discussing personal problems within a dyadic relationship and is characterized by frequently discussing problems, discussing the same problem repeatedly, mutual encouragement of discussing problems, speculating about problems, and focusing on negative feelings" (p. 1830). Co-rumination typically occurs in the context of high-quality friendships and includes positive friendship adjustment such as sharing thoughts and feelings, but co-rumination can also exacerbate symptoms of depression. Criss et al. (2016) found that peer co-rumination was directly and indirectly related to youth depressive symptoms, with no differences found by race/ ethnicity. Considering research that has pointed to greater levels of rumination among AA than European American college students (Chang et al., 2010), future research should examine co-rumination in friendships to identify its impact on the risk or protective nature of peer support on important mental health outcomes.

This finding may also be explained by variations in the assessment of the construct of peer support. In the current study, peer support within the school context was assessed. Youth may have other sources of peer support that were not accounted for in the present study. For instance, previous studies examining peer support as a buffer in the relationship 
between peer victimization and depressive symptoms have mostly assessed support from best or close friends (Grossman \& Liang, 2008; Hodges et al., 1999; Schmidt \& Bagwell, 2007; Tanigawa et al., 2011) with different findings. Future research should include measures of peer support within different contexts and seek to examine both general support and support from close friends. This will contribute to additional understanding of within-group variation in how different aspects of peer support might function as protective or risk factors on the relationship between peer victimization and depressive symptoms in this understudied group.

Finally, despite research finding differences in the association between peer victimization, peer support, and depression by gender (Davidson \& Demaray, 2007; Tanigawa et al., 2011), the current study did not find support for this three-way interaction, suggesting that this relationship operates similarly for both AA boys and girls. This finding is inconsistent with prior research with primarily White and Latinx samples (e.g., Davidson \& Demaray, 2007; Schmidt \& Bagwell, 2007; Tanigawa et al., 2011) finding differences by gender. Thus, these findings suggest that this relationship may function differently among AA boys or girls or may simply be as a result of a smaller sample size in the current study. Additional research clarifying the role of gender in these relationships among AA is needed.

\section{Limitations and Future Directions}

Results should be interpreted in light of the study's limitations. First, AA were not examined by subgroup or national origin (e.g., Japanese, Korean, etc.) because this information was not collected in the parent study. Considering recent evidence supporting differences in depressive symptoms within AA subgroups (Okamura et al., 2016), future research should examine similarities or differences in the relationship between peer victimization and depression and the moderating role of peer support within AA subgroups. Second, differences in subtypes of peer victimization (e.g., physical, verbal, relational) were not considered. As past research has found differences in subtypes of peer victimization by gender (Nansel et al., 2001) and the link between race-based bullying and discrimination has been highlighted (Shin et al., 2011), future research should take into account types of peer victimization, making sure to 
directly probe race-based bullying. Third, the current study was also unable to include relevant cultural variables such as generational status or level of acculturation, which may be important to consider (Yoshikawa, Mistry, \& Wang, 2016). Future research should seek to consider the role of these potentially relevant variables. Fourth, there were measurement limitations. We used a proxy (i.e., social mobility) as a measure of SES rather than a direct measurement of family income. A more comprehensive measure of peer support, which examines emotional, informational, and instrumental support for instance (Holt \& Espelage, 2007), was not available. Additionally, only self-report measures were used; thus, single-reporter bias cannot be ruled out (e.g., the degree to which reports of peer victimization and peer support are influenced by levels of depressive symptoms). Moreover, while the measure of depressive symptoms had been abbreviated and validated in prior work (e.g., Poulsen et al., 2016), the version used in this study varied from these validated versions. Abbreviations were made to address administration burdens in the context of a large-scale data collection effort. Relatedly, our measure of peer victimization assessed experiences of peer victimization over the previous calendar year; this differs from many measures of peer victimization which assess experiences of peer victimization over the past 30 days or academic year (Vivolo-Kantor, Martell, Holland, \& Westby, 2014). Future research should seek to attend to these methodological limitations. Fifth, participants were recruited from one county in the Midwest with $50 \%$ of parents providing consent. The findings provide insight into the mental health of the sample, yet, the generalizability of the findings is limited and may be influenced by selection bias. The inclusion of AA youth from various areas of the USA would help confirm the generalizability of these findings.

\section{Implications}

Findings underscore the potentially important role of peer victimization in the prevention of depressive symptoms among AA early adolescents. As a critical initial step, efforts are needed that are aimed at increasing awareness among educators and school-based mental health providers regarding the prevalence of peer victimization and depression among AA early adolescents. Professional development programs that seek to dispel model minority myths held by educators and other 
school-based providers, which may interfere with recognition of mental health needs among AA early adolescents, may prove beneficial (Cheng et al., 2016). Next, there is a strong need for schools to implement culturally responsive school mental health initiatives aimed at reducing peer victimization among AA early adolescents (Hong et al., 2014). Such programs should seek to address culturally relevant factors, such as immigration status, language issues, and violation of AA stereotypes (Huang \& Vidourek, 2019). Further, such programming should include a focus on respect for diversity and ways to create a welcoming and inclusive school climate (Gage, Prykanowski, \& Larson, 2014). Moreover, depression intervention programming may seek to address coping related to peer victimization among this underserved group (La Greca, Ehrenreich-May, Mufson, \& Chan, 2016). Finally, attention to the varying role of peer support across contexts will be needed when considering future depression intervention programming for early adolescent AA youth. In particular, with an awareness that aspects of peer support in the school context may be risk enhancing, encouragement of building multiple types of support (e.g., family, neighborhood, teacher, religious contexts) may also prove beneficial (Arora et al., 2017; Zhou et al., 2012).

\section{Conclusion}

The current study contributes to our understanding of AA youth by examining the prospective relationship between experiences of peer victimization and depressive symptoms, as well as the moderating roles of peer support and gender. The findings suggest that peer victimization does indeed lead to increased depressive symptoms for AA early adolescent youth. Further, while gender was not shown to moderate this relationship, peer support was. For youth reporting high levels of peer support, the association between peer victimization and depressive symptoms was exacerbated. These results suggest the need to examine peer relationships more closely to inform research on preventive-intervention programming aimed at supporting positive youth development among AA early adolescents. 
Ethical Standards - Human and Animal Rights All procedures performed in studies involving human participants were in accordance with the ethical standards of the institutional research committee and with the 1964 Helsinki declaration and its later amendments or comparable ethical standards. Informed consent was obtained from all individual participants included in the study. The authors declare they have no competing or potential conflicts of interest.

\section{References}

Aiken, L. S., \& West, S. G. (1991). Multiple regression: Testing and interpreting interactions. Newbury Park, CA: Sage.

Arora, P. G., Wheeler, L. A., Fisher, S., \& Barnes, J. (2017). A prospective examination of anxiety as a predictor of depressive symptoms among Asian American early adolescent youth: The role of parent, peer, and teacher support and school engagement. Cultural Diversity and Ethnic Minority Psychology, 23(4), 541-550. doi:10.1037/cdp0000168

Asian American Federation. (2014). The state of Asian American children. http:// www.aafederation.org/doc/AAF StateofAsianAmericanChildren.pdf

Barnes, J., Almerigi, J., \& Hsu, W. W. (2009). Coordinated community assessment: Data from the coordinated community student survey. Retrieved July 19, 2020, from http://cerc.msu.edu/research/pastprojects.aspx

Baumeister, R. F., \& Leary, M. R. (1995). The need to belong: Desire for interpersonal attachments as a fundamental human motivation. Psychological Bulletin, 117(3), 497-529.

Bond, L., Carlin, J. B., Thomas, L., Rubin, K., \& Patton, G. (2001). Does bullying cause emotional problems? A prospective study of young teenagers. BMJ, 323(7311), 480-484. doi:10.1136/bmj.323.7311.480

Bradley, R., \& Corwyn, R. F. (2002). Socioeconomic status and child development. Annual Review of Psychology, 53, 371-399. doi:10.1146/annurev. psych.53.100901.135233

Brown, J. S., Meadows, S. O., \& Elder, G. H. (2007). Race-ethnic inequality and psychological distress: Depressive symptoms from adolescence to young adulthood. Developmental Psychology, 43(6), 1295-1311. doi:10.1037/0012-1649.43.6.1295

Carlyle, K. E., \& Steinman, K. J. (2007). Demographic differences in the prevalence, co-occurrence, and correlates of adolescent bullying at school. Journal of School Health, 77(9), 623-629.

Chang, E. C., Tsai, W., \& Sanna, L. J. (2010). Examining the relations between rumination and adjustment: Do ethnic differences exist between Asian and European Americans? Asian American Journal of Psychology, 1(1), 46-56. doi:10.1037/a0018821 
Chen, A., Haas, S., Gillmore, M., \& Kopak, A. (2011). Trajectories of depressive symptoms from adolescence to young adulthood: Chinese Americans versus nonHispanic whites. Research in Nursing \& Health, 34(3), 176-191. doi:10.1002/ nur.20429

Cheng, A. W., Chang, J., O’Brien, J., Budgazad, M. S., \& Tsai, J. (2016). Model minority stereotype: Influence on perceived mental health needs of Asian Americans. Journal of Immigrant and Minority Health, 19(3), 572-581. doi:10.1007/ s10903-016-0440-0

Choi, H., Meininger, J. C., \& Roberts, R. E. (2006). Ethnic differences in adolescents' mental distress, social stress, and resources. Adolescence, 41(162), 263-283.

Cooc, N., \& Gee, K. A. (2014). National trends in school victimization among Asian American adolescents. Journal of Adolescence, 37(6), 839-849. doi:10.1016/j. adolescence.2014.05.002

Criss, M. M., Houltberg, B. J., Cui, L., Bosler, C. D., Sheffield Morris, A., \& Silk, J. S. (2016). Direct and indirect links between peer factors and adolescent adjustment difficulties. Journal of Applied Developmental Psychology, 43, 83-90. doi:10.1016/j. appdev.2016.01.002

Davidson, L. M., \& Demaray, M. K. (2007). Social support as a moderator between victimization and internalizing-externalizing distress from bullying. School Psychology Review, 36, 383-405.

Desjardins, T. L., \& Leadbeater, B. J. (2011). Relational victimization and depressive symptoms in adolescence: moderating effects of mother, father, and peer emotional support. Journal of Youth and Adolescence, 40(5), 531-544. doi:10.1007/s10964-010-9562-1

Enders, C. K. (2010). Applied missing data analysis. Guilford: The Guilford Press.

Espelage, D. L., \& Swearer, S. M. (2010). A social-ecological model for bullying prevention and intervention: Understanding the impact of adults in the social ecology of youngsters. In S. R. Jimerson, S. M. Swearer, \& D. L. Espelage (Eds.), Handbook of bullying in schools: An international perspective (pp. 61-72). London: Routledge. doi:10.4324/9780203842898

Fisher, C. B., Wallace, S. A., \& Fenton, R. E. (2000). Discrimination distress during adolescence. Journal of Youth and Adolescence, 29(6), 679-695. doi:10.1023/A:1026455906512

Fisher, S., Wheeler, L. A., Arora, P. G., Chaudry, J., \& Barnes-Najor, J. (2019). Ethnic identity and substance use in multiracial youth: The moderating role of support networks. Substance Use and Misuse, 54(9), 1417-1428. doi:10.1080/10826084.2 019.1573834

Gage, N. A., Prykanowski, D. A., \& Larson, A. (2014). School climate and bullying victimization: A latent class growth model analysis. School Psychology Quarterly, 29(3), 256-271. doi:10.1037/spq0000064

García Coll, C., Lamberty, G., Jenkins, R., McAdoo, H. P., Crnic, K., Wasik, B. H., et al. (1996). An integrative model for the study of developmental competencies in minority children. Child Development, 67, 1891-1914. doi:10.2307/1131600

Gilbert, P. (1992). Depression: The evolution of powerlessness. Guilford: The Guilford Press. 
Gredler, G. R. (2003). Review of the book Bullying at school: What we know and what we can do, by D. Olweus. Psychology in the Schools, 40(6), 699-700. doi:10.1002/ pits.10114

Greenberger, E., \& Chen, C. (1996). Perceived family relationships and depressed mood in early and late adolescence: A comparison of European and Asian Americans. Developmental Psychology, 32(4), 707-716. doi:10.1037/0012-1649.32.4.707

Grossman, J., \& Liang, B. (2008). Discrimination distress among Chinese American adolescents. Journal of Youth and Adolescence, 37(1), 1-11. doi:10.1007/ s10964-007-9215-1

Harter, S. (1999). The construction of self: A developmental perspective. Guilford: The Guilford Press.

Hodges, E. V. E., Boivin, M., Vitaro, F., \& Bukowski, W. M. (1999). The power of friendship: Protection against an escalating cycle of peer victimization. Developmental Psychology, 35(1), 94-101. doi:10.1037/0012-1649.35.1.94

Hoeffel, E. M., Rastogi, S., Kim, M. O., \& Shahid, H. (2012). The Asian population: 2010. U. S. Census Bureau. https://www.census.gov/prod/cen2010/briefs/c2010br-11. pdf

Holt, M., \& Espelage, D. (2007). Perceived social support among bullies, victims, and bully-victims. Journal of Youth and Adolescence, 36(8), 984-994. doi:10.1007/ s10964-006-9153-3

Huang, S., \& Vidourek, R. A. (2019). Bullying victimization among Asian-American youth: A review of the literature. International Journal of Bullying Prevention, 1, 187-204. doi:10.1007/s42380-019-00029-3

Juang, L. P., Syed, M., \& Cookston, J. T. (2012). Acculturation-based and everyday parent-adolescent conflict among Chinese American adolescents: Longitudinal trajectories and implications for mental health. Journal of Family Psychology, 26(6), 916-926. doi:10.1037/a0030057

Kaltiala-Heino, R., Fröjd, S., \& Marttunen, M. (2010). Involvement in bullying and depression in a 2-year follow-up in middle adolescence. European Child and Adolescent Psychiatry, 19(1), 45-55. doi:10.1007/s00787-009-0039-2

Kawabata, Y., Tseng, W. L., \& Crick, N. R. (2013). Adaptive, maladaptive, mediational, and bidirectional processes of relational and physical aggression, relational and physical victimization, and peer liking. Aggressive Behavior, 40(3), 273-287. doi:10.1002/ab.21517

Kiang, L., Tseng, V., \& Yip, T. (2016). Placing Asian American child development within historical context. Child Development, 87(4), 995-1013. doi:10.1111/ cdev.12578

Kim, T. E., \& Goto, S. G. (2000). Peer delinquency and parental social support as predictors of Asian American adolescent delinquency. Deviant Behavior, 21(4), 331-347. doi:10.1080/016396200404122

Kochel, K. P., Bagwell, C. L., Ladd, G. W., \& Rudolph, K. D. (2017). Do positive peer relations mitigate transactions between depressive symptoms and peer victimization in adolescence? Journal of Applied Developmental Psychology, 51, 44-54. doi:10.1016/j.appdev.2017.04.003 
Kochel, K. P., Ladd, G. W., \& Rudolph, K. D. (2012). Longitudinal associations among youth depressive symptoms, peer victimization, and low peer acceptance: An interpersonal process perspective. Child Development, 93(2), 637-650. doi:10.1111/j.1467-8624.2011.01722.x

Koo, D. J., Peguero, A. A., \& Shekarkhar, Z. (2012). The "model minority" victim: Immigration, gender, and Asian American vulnerabilities to violence at school. Journal of Ethnicity in Criminal Justice, 10(2), 129-147. doi:10.1080/15377938.2 011.609405

La Greca, A. M., Ehrenreich-May, J., Mufson, L., \& Chan, S. (2016). Preventing adolescent social anxiety and depression and reducing peer victimization: Intervention development and open trial. Child \& Youth Care Forum, 45, 905-926. doi:10.1007/s10566-016-9363-0

Liang, B., Grossman, J. M., \& Deguchi, M. (2007). Chinese American middle school youths' experiences of discrimination and stereotyping. Qualitative Research in Psychology, 4(1-2), 187-205. doi:10.1080/14780880701473599

Lorenzo, M. K., Frost, A. K., \& Reinherz, H. Z. (2000). Social and emotional functioning of older Asian American adolescents. Child and Adolescent Social Work Journal, 17(4), 289-304. doi:10.1023/A:1007598007205

McLoyd, V. (1990). The impact of economic hardship on black families and children: Psychological distress, parenting, and socioemotional development. Child Development, 61(2), 311-346. doi:10.2307/1131096

Mistry, J., \& Dutta, R. (2015). Human development and culture. In W. F. Overton, P. C. M. Molenaar, \& R. M. Lerner (Eds.), Handbook of child psychology and developmental science: Theory and method (pp. 369-406). New York: Wiley. doi:10.1002/9781118963418.childpsy110

Mistry, J., Li, J., Yoshikawa, H., Tseng, V., Tirrell, J. M., Kiang, L., et al. (2016). An integrated conceptual framework for the development of Asian American children and youth. Child Development, 87(4), 1014-1032. doi:10.1111/cdev.12577

Mouttapa, M., Valente, T., Gallaher, P., Rohrback, L. A., \& Unger, J. B. (2004). Social network predictors of bullying and victimization. Adolescence, 39(154), 315-335.

Muthén, L.K. \& Muthén, B.O. (1998-2014). Mplus user's guide (7th ed.)

Nansel, T. R., Overpeck, M., Pilla, R. S., Ruan, W. J., Simons-Morton, B., \& Scheidt, P. (2001). Bullying behaviors among US youth: prevalence and association with psychosocial adjustment. JAMA, 285(16), 2094-2100.

National Center for Education Statistics. (2012). The condition of education. https:// nces.ed.gov/pubs2012/2012045.pdf

Nolen-Hoeksema, S. (2001). Gender differences in depression. Current Directions in Psychological Science, 10(5), 173-176. doi:10.1111/1467-8721.00142

Okagaki, L., \& Bojczyk, K. E. (2002). Perspectives on Asian American development. In G. C. NagayamaHall \& S. Okazaki (Eds.), Asian American psychology: The science of lives in context (pp. 67-104). Worcester: American Psychological Association. doi:10.1037/10473-003

Okamura, K. H., Ebesutani, C., Bloom, R., Higa-McMillan, C. K., Nakamura, B. J., \& Chorpita, B. F. (2016). Differences in internalizing symptoms across specific 
ethnic minority groups: An analysis across Chinese American, Filipino American, Japanese American, Native Hawaiian, and White youth. Journal of Child and Family Studies, 25(11), 3353-3366. doi:10.1007/s10826-016-0488-4

Pellegrini, A. D., \& Long, J. D. (2004). Part of the solution and part of the problem: The role of peers in bullying, dominance, and victimization during the transition from primary school through secondary school. In D. L. Espelage \& S. M. Swearer (Eds.), Bullying in American schools: A social-ecological perspective on prevention and intervention (pp. 107-117). Mahwah: Lawrence Erlbaum Associates Publishers.

Poulsen, K. M., Pachana, N. A., \& McDermott, B. M. (2016). Health professionals' detection of depression and anxiety in their patients with diabetes: The influence of patient, illness and psychological factors. Health Psychology, 21(8), 1566-1575. doi:10.1177/1359105314559618

Radloff, L. S. (1977). The CES-D Scale: A self-report depression scale for research in the general population. Applied Psychological Measurement, 1, 385-401. doi:10.1177/014662167700100306

Rivas-Drake, D., Hughes, D., \& Way, N. (2008). A closer look at peer discrimination, ethnic identity, and psychological well-being among urban Chinese American sixth graders. Journal of Youth and Adolescence, 37(1), 12-21. doi:10.1007/ s10964-007-9227-x

Rohde, P., Beevers, C. G., Stice, E., \& O’Neil, K. (2009). Major and minor depression in female adolescents: onset, course, symptom presentation, and demographic associations. Journal of Clinical Psychology, 65(12), 1339-1349. doi:10.1002/ jclp.20629

Rose, A. J. (2002). Co-rumination in the friendships of girls and boys. Child Development, 73(6), 1830-1843. doi:10.1111/1467-8624.00509

Rudolph, K. D. (2009). Adolescent depression. In I. H. Gotlib \& C. L. Hammen (Eds.), Handbook of depression (pp. 444-466). Guilford: The Guilford Press.

Rueger, S. Y., Malecki, C. K., \& Demaray, M. K. (2008). Gender differences in the relationship between perceived social support and student adjustment during early adolescence. School Psychology Quarterly, 23(4), 496-514. doi:10.1037/1045-3830.23.4.496

Schmidt, M. E., \& Bagwell, C. L. (2007). The protective role of friendships in overtly and relationally victimized boys and girls. Merrill-Palmer Quarterly, 53(3), 439460. doi:10.1353/mpq.2007.0021

Schwartz, D., Gorman, A. H., Nakamoto, J., \& Toblin, R. L. (2005). Victimization in the peer group and children's academic functioning. Journal of Educational Psychology, 97(3), 425-435. doi:10.1037/0022-0663.97.3.425

Sentse, M., Prinzie, P., \& Salmivalli, C. (2016). Testing the direction of longitudinal paths between victimization, peer rejection, and different types of internalizing problems in adolescence. Journal of Abnormal Child Psychology, 45(5), 10131023. doi:10.1007/s10802-016-0216-y

Shin, J. Y., D’Antonio, E., Son, H., Kim, S. A., \& Park, Y. (2011). Bullying and discrimination experiences among Korean-American adolescents. Journal of Adolescence, 34(5), 873-883. doi:10.1016/j.adolescence.2011.01.004 
Sweeting, H., Young, R., West, P., \& Der, G. (2006). Peer victimization and depression in early-mid adolescence: A longitudinal study. British Journal of Educational Psychology, 76(3), 577-594.

Tanigawa, D., Furlong, M. J., Felix, E. D., \& Sharkey, J. D. (2011). The protective role of perceived social support against the manifestation of depressive symptoms in peer victims. Journal of School Violence, 10(4), 393-412. doi:10.1080/15388220. 2011.602614

Tran, C. V., Cole, D. A., \& Weiss, B. (2012). Testing reciprocal longitudinal relations between peer victimization and depressive symptoms in young adolescents. Journal of Clinical Child and Adolescent Psychology, 41(3), 353-360. doi:10.1080/1 5374416.2012.662674

U.S. Census Bureau. (2010). State \& county QuickFacts: Genesee County, MI. Retrieved February 21, 2017, from https://factfinder.census.gov/faces/ tableservices/isf/pages/productview.xhtml?src=bkmk

Vivolo-Kantor, A. M., Martell, B. N., Holland, K. M., \& Westby, R. (2014). A systematic review and content analysis of bullying and cyber-bullying measurement strategies. Aggression and Violent Behavior, 19(4), 423-434. doi:10.1016/j. avb.2014.06.008

Wyatt, L. C., Ung, T., Park, R., Kwon, S. C., \& Chau, T. S. (2015). Risk factors of suicide and depression among Asian American, Native Hawaiian, and Pacific Islander youth: A systematic literature review. Journal of Health Care for the Poor and Underserved, 26(2), 191-237. doi:10.1353/hpu.2015.0059

Yeh, C. J., Liao, H.-Y., Ma, P.-W. W., Shea, M., Okubo, Y., Kim, A. B., et al. (2014). Ecological risk and protective factors of depressive and anxiety symptoms among low-income, Chinese immigrant youth. Asian American Journal of Psychology, 5(3), 190-199. doi:10.1037/a0034105

Yoshikawa, H., Mistry, R., \& Wang, Y. (2016). Advancing methods in research on Asian American children and youth. Child Development, 87(4), 1. doi:10.1111/ cdev.12576.

Zhou, Q., Tao, A., Chen, S. H., Main, A., Lee, E., Ly, J., et al. (2012). Asset and protective factors for Asian American children's mental health adjustment. Child Development Perspectives, 6(3), 213-219. doi:10.1111/j.1750-8606.2012.00251.x 